\title{
Perbandingan Hasil Tomato (Lycopersicon esculentum Mill. cv MT1) menggunakan Kompos Tandan Buah Kosong (EFB) dan Kompos Najis Lembu sebagai Medium Penanaman
}

(Comparison of Tomato (Lycopersicon esculentum Mill. cv MT1) Yield using Empty Fruit Bunch (EFB) and Cow Manure Compost as Planting Medium)

\author{
Aishah Elias, Safiyyah Shahimi, Haslaniza Hashim, Sahilah AbD. MutaliB* \& Wan Aida Wan \\ MUSTAPHA
}

\begin{abstract}
ABSTRAK
Kajian dalam rumah kaca telah dijalankan untuk mengkaji kesan pestisid, kompos dan baja terhadap hasil tomato (Lycopersicon esculentum Mill. cv MT1) bermula dari April sehingga Disember 2015. Reka bentuk uji kaji yang digunakan semasa penanaman pokok tomato adalah 'split-split plot'. Faktor yang diambil kira terbahagi kepada tiga peringkat dengan faktor utama merupakan kesan pestisid, faktor peringkat dua ialah rawatan baja dan faktor peringkat tiga ialah jenis kompos. Sejumlah enam belas (n=16) rawatan telah diberikan iaitu T1 sehingga T16. Keputusan kajian menunjukkan ketinggian pokok tertinggi bagi setiap bulan adalah daripada perlakuan yang berbeza manakala dari segi berat, didapati T10 menghasilkan berat daun paling tinggi (200.0 g), T6 menunjukkan berat batang yang paling tinggi (261.3 g) dan T3 menunjukkan berat akar yang paling tinggi (91.0 g). Perlakuan T12 $(73.0 \mathrm{~cm})$ menunjukkan nilai paling tinggi bagi panjang akar manakala saiz daun yang paling besar ditunjukkan oleh T11 $\left(48.0 \mathrm{~cm}^{2}\right)$. T15 menunjukkan berat buah yang tertinggi $(560.3 \mathrm{~g})$ dan bilangan buah bagi setiap pokok (32 buah) secara signifikan $(p<0.05)$ tetapi tidak signifikan $(p>0.05)$ dalam diameter buah $(30.47 \mathrm{~mm})$. Walau bagaimanapun, T12 menunjukkan nilai yang tidak signifikan ( $p>0.05)$ bagi berat buah (532.5 g) dan bilangan buah (17 buah) tetapi signifikan $(p<0.05)$ bagi diameter buah $(39.61 \mathrm{~mm})$. Oleh itu, dalam kajian ini menunjukkan rawatan T15 (pestisid organik, kompos najis lembu sebagai medium penanaman dan baja kimia dan organik) menghasilkan jumlah berat dan bilangan yang signifikan $(p<0.05)$ dalam buah tomato.
\end{abstract}

Kata kunci: Hasil dan baja; kompos tandan buah kosong (EFB); kompos najis lembu; penanaman; tomato (Lycopersicon esculentum Mill. cv MT1)

\section{ABSTRACT}

A glasshouse study was conducted to study the effect of pesticides, type of compost, and different treatment of fertilizer on tomato (Lycopersicon esculentum Mill. cv MT1) yield from April to December 2015. The tomato plants were tested using split-split plot experimental design. The effect of pesticides was the main factor, the sub factor was different treatment of fertilizers and sub-sub factor was types of compost. A total of sixteen ( $n=16)$ treatments were designed namely as T1 to T16. The results showed that the highest plant height for every month were from different treatments while highest leaf weight was shown by T10 (200.0 g), highest stem weight was by T6 (261.3 g) and highest root weight was T3 (91.0 g). Longest root was shown by T12 (73.0 cm) while widest leaf area showed by T11 $\left(48 \mathrm{~cm}^{2}\right)$ and T3 $\left(19.78 \mathrm{~cm}^{2}\right)$ significantly $(p<0.05)$. T15 showed significantly $(p<0.05)$ highest of total fruit weight $(560.3 \mathrm{~g})$ and number of fruits per plant (32 fruits), but not significant $(p>0.05)$ in fruit diameter $(30.47 \mathrm{~mm})$. Although T12 showed not significant $(p>0.05)$ for total fruit weight $(532.5 \mathrm{~g})$ and total fruit per plant (17 fruits) but significant $(p<0.05)$ in the fruit diameter $(39.61 \mathrm{~mm})$. Thus, this study demonstrated the combination treatment on tomato plant for T15 (organic pesticide, cow manure as medium of growth and chemical and organic fertilizer) produced significant $(p<0.05)$ yield total weight and fruit count of tomato fruits.

Keywords: Cow manure compost; empty fruit bunch (EFB) compost; growth; tomato (Lycopersicon esculentum Mill. cv MT1); yield and fertilizer 


\section{PENGENALAN}

Kelapa sawit merupakan industri penanaman yang besar di Malaysia dan merupakan yang kedua terbesar di dunia. Pengeluaran kelapa sawit negara menyumbang kepada $50 \%$ iaitu sebanyak 10.8 tan produk kelapa sawit dunia. Pada tahun 2011, kelapa sawit merupakan penyumbang keempat terbesar dengan nilai RM53 billion (USD16.8 billion) pendapatan negara kasar (GNI). Sisa kilang kelapa sawit adalah efluen kelapa sawit (POME), kek dandang, tandan buah kosong (EFB), cengkerang biji dan fiber daripada mesokarpa. Keseluruhannya, sebanyak 20 hingga $20 \%$ tandan buah kosong (EFB) terhasil daripada tandan buah penuh kelapa sawit (Mahlia et al. 2001; Singh et al. 2011).

Terdapat pelbagai jenis media penanaman seperti tanah pit, pasir, pit kelapa, tanah hitam dan tanah mineral yang boleh digunakan untuk penanaman. Ia boleh digunakan secara sendirian atau gabungan dengan nisbah antara keseluruhan medium penanaman. Pemilihan setiap nisbah bergantung kepada jenis tanaman dan cara tanaman ditanam sama ada di kawasan terbuka, dalam pasu atau dalam tangki (Douglass et al. 2009). Antara nisbah isi padu medium penanaman yang boleh digunakan ialah 3:2:1 merujuk kepada nisbah tanah: pasir: kompos. Nisbah campuran lain boleh juga digunakan bergantung kepada kesesuaian tanaman yang hendak ditanam. Kajian oleh Getachew (2014) menunjukkan bahawa nisbah campuran tanah akan memberi kesan terhadap pertumbuhan dan kemandirian benih. Penggunaan kompos daripada sumber tumbuhan seperti EFB dalam campuran medium penanaman juga boleh menggalakkan pertumbuhan dan meningkatkan kualiti buah (Farahzety et al. 2009; Ismail et al. 2004; Wira et al. 2011).

Pengkomposan merupakan kaedah hijau yang boleh menukarkan sisa pertanian kepada produk bernilai yang boleh mengimbangi ciri-ciri kimia tanah (Ennis et al. 2005). Proses yang berasaskan konsep biologi ini boleh menstabilkan bahan organik untuk pembetulan tanah dan melindungi persekitaran daripada kesan kerosakan akibat produk sisa (Asis et al. 2017; Noor et al. 2012). Selain digunakan sebagai kompos, EFB juga boleh digunakan dalam penghasilan gas hidrogen (Chong et al. 2013). Jika dijalankan dengan betul, sisa pertanian boleh diguna semula dan boleh menghasilkan sistem sisa sifar dalam pertanian. Oleh sebab itu, penggunaan EFB sebagai kompos dalam skala besar disokong oleh Dasar Pertanian Agromakanan 2011-2020 dan akan menyeimbangkan aktiviti pertanian dan menyediakan persekitaran yang mampan.

Disebabkan EFB merupakan sisa yang banyak, ia sesuai untuk digunakan semula untuk menerapkan konsep 'waste to wealth' melalui strategi pengurusan sisa dengan faedah ekonomi dan persekitaran. Kompos EFB akan digunakan sebagai baja organik di dalam ladang kelapa sawit. Sementara itu, najis lembu merupakan kompos yang berasal daripada sumber haiwan yang digunakan oleh kebanyakan petani. Penggunaan kompos najis lembu juga dipercayai dapat memulihkan struktur tanah sama seperti kompos EFB. Walau bagaimanapun, kandungan nutrisi kompos EFB dan kompos najis lembu dari segi mineral adalah berbeza. Dalam kajian ini, perbandingan antara dua jenis kompos sebagai medium penanaman tomato akan dilakukan dari segi pertumbuhan dan jumlah hasil. Tomato dipilih kerana nilai ekonomi dan merupakan produk pertanian yang kompetetif di pasaran (Roslina \& Rozhan 2014).

\section{BAHAN DAN KAEDAH}

\section{BAHAN PENANAMAN}

Benih tomato (Lycopersicon esculentum Mill. cv MT1) yang diperoleh dari Institut Penyelidikan dan Pertanian (MARDI) pada bulan Februari 2015 (no rujukan 10/12/ B3). Benih disemai pada April 2015 dan dipindahkan dari tapak semaian selepas 28 hari disemai. Dua jenis kompos digunakan dalam medium penanaman iaitu tandan buah kosong (EFB) dan najis lembu. EFB diperoleh dari Pusat Pengomposan Sime Darby Flemington, Bagan Datuk, Perak, Malaysia dan najis lembu dibekalkan oleh Kompleks Rumah Tumbuhan, Universiti Kebangsaan Malaysia (UKM).

\section{REKA BENTUK UJI KAJI}

Kajian rumah kaca dijalankan di Kompleks Rumah Tumbuhan, UKM, Selangor di lokasi $2.92^{\circ} \mathrm{N}$ and $101.78^{\circ} \mathrm{E}$ bermula dari April sehingga Disember 2015. Medium penanaman disediakan dengan mengaduk tanah, pasir dan kompos dalam nisbah 3:2:1 menggunakan pengaduk tanah. Medium penanaman kemudiannya diisi ke dalam beg polietilena yang bersaiz $40.64 \mathrm{~cm}^{2}$ dengan tiga replikasi. Kajian dijalankan menggunakan susunan splitsplit plot.

Plot utama merupakan jenis pestisid dengan dua jenis rawatan iaitu kimia (Malathion dan Confidor, Bayer, NZ) dan organik (Serotech, MY). Faktor ini dipilih sebagai plot utama kerana merupakan faktor paling sukar dimanipulasi oleh penyelidik. Tirai kain daripada jenis fabrik net digunakan untuk memisahkan plot rawatan menggunakan pestisid. Faktor peringkat dua ialah rawatan baja iaitu tanpa baja, baja organik, baja kimia dan campuran baja organik dan kimia. Faktor peringkat tiga ialah jenis kompos iaitu kompos EFB dan kompos najis lembu. Gabungan faktor bagi semua peringkat rawatan dalam Jadual 1. 
JADUAL 1. Perlakuan terhadap pokok tomato

\begin{tabular}{|c|c|c|c|}
\hline $\begin{array}{l}\text { Faktor utama - jenis } \\
\text { pestisid }\end{array}$ & Faktor ke dua - jenis baja & Faktor ke tiga - jenis kompos & Perlakuan \\
\hline \multirow{8}{*}{$\begin{array}{l}\text { Pestisid kimia } \\
\text { (Malathion dan } \\
\text { Confidor) }\end{array}$} & \multirow[t]{2}{*}{ Tanpa baja } & Najis lembu & $\mathrm{T} 1$ \\
\hline & & $\mathrm{EFB}$ & $\mathrm{T} 2$ \\
\hline & \multirow[t]{2}{*}{ Baja organik (AgroPlus) } & Najis lembu & $\mathrm{T} 3$ \\
\hline & & EFB & $\mathrm{T} 4$ \\
\hline & \multirow[t]{2}{*}{ Baja kimia (NPK 15:15:15) } & Najis lembu & $\mathrm{T} 5$ \\
\hline & & EFB & T6 \\
\hline & \multirow[t]{2}{*}{ Campuran baja kimia dan organik } & Najis lembu & $\mathrm{T} 7$ \\
\hline & & EFB & $\mathrm{T} 8$ \\
\hline \multirow{8}{*}{$\begin{array}{l}\text { Pestisid organik } \\
\text { (Serotech, MY) }\end{array}$} & \multirow[t]{2}{*}{ Tanpa baja } & Najis lembu & T9 \\
\hline & & EFB & $\mathrm{T} 10$ \\
\hline & \multirow[t]{2}{*}{ Baja organik (AgroPlus) } & Najis lembu & $\mathrm{T} 11$ \\
\hline & & EFB & $\mathrm{T} 12$ \\
\hline & \multirow[t]{2}{*}{ Baja kimia (NPK 15:15:15) } & Najis lembu & $\mathrm{T} 13$ \\
\hline & & $\mathrm{EFB}$ & $\mathrm{T} 14$ \\
\hline & Campuran baja kimia dan & Najis lembu & $\mathrm{T} 15$ \\
\hline & organik & EFB & $\mathrm{T} 16$ \\
\hline
\end{tabular}

Kesemua enam belas perlakuan adalah rawak dalam setiap replikasi. Baja kimia mengandungi nitrogen $15 \%$, fosforus $15 \%$ and kalium $15 \%$ digunakan. Baja organik (Agroplus) dengan kandungan nitrogen 3\%, fosforus 4\% dan kalium 7\% daripada DUHC Technologies Sdn. Bhd.
(DUHC Technologies, MY). Kajian yang telah dijalankan terhadap medium EFB dan medium najis lembu untuk mengenal pasti kandungan nutrisi medium seperti dalam Jadual 2.

JADUAL 2. Kandungan jumlah nitrogen, fosforus, kalium, magnesium, kalsium, zink dan kuprum dalam kedua-dua medium penanaman

\begin{tabular}{lll}
\hline \multirow{2}{*}{ Jumlah nutrien } & \multicolumn{2}{c}{ Medium penanaman } \\
\cline { 2 - 3 } & Tandan buah kosong (EFB) & Najis lembu \\
\hline Karbon, C \% & 1.198 & 1.899 \\
Nitrogen, N \% & 0.270 & 0.635 \\
Fosforus, P ppb & 1.501 & 0.202 \\
Kalium, K ppb & 0.176 & 0.077 \\
Magnesium, Mg ppb & 1.712 & 1.016 \\
Kalsium, Ca ppb & 0.688 & 0.793 \\
Zink, Zn ppb & 0.169 & 0.135 \\
Kuprum, Cu ppb & 0.025 & 0.006 \\
\hline
\end{tabular}


Pengairan pokok tomato menggunakan air paip sebanyak enam kali sehari iaitu pada jam 7 pagi, 9 pagi, 11 pagi, 1 petang, 3 petang, 5 petang dan 9 malam selama 5 minit setiap kitaran bagi membekalkan air yang mencukupi kepada pokok. Perlakuan menggunakan baja dan pestisid diberi sekali setiap dua minggu secara bergilir. Semua pokok tomato dituai pada hujung Disember 2015 selepas lapan bulan ditanam.

\section{PENGUKURAN PERTUMBUHAN DAN HASIL}

Tinggi pokok dari tanah hingga ke pucuk diukur setiap bulan. Setelah pokok dipotong, bahagian pokok diasingkan kepada daun, batang dan akar dan kemudian dikeringkan dalam ketuhar (Memmert, GY) pada suhu 50 ${ }^{\circ} \mathrm{C}$ selama tujuh hari. Berat daun, batang dan akar diukur seperti dalam Mohd. Razi dan Dalia (1995). Buah dipetik apabila berubah warna daripada kuning ke merah iaitu pada indeks kematangan 5. Jumlah berat buah diukur. Bilangan buah setiap pokok juga direkodkan dan diameter buah diukur menggunakan angkup Vernier.

\section{ANALISIS STATISTIK}

Analisis varians bagi reka bentuk split-split plot dilakukan menggunakan model linear umum (GLM) SAS 9.1. Semua analisis ini diikuti dengan ujian pos hoc perbezaan signifikan terkecil (LSD) pada aras keyakinan 5\% bagi perbezaan antara perlakuan apabila keputusan adalah signifikan.

\section{HASIL DAN PERBINCANGAN}

Dalam kajian ini enam belas perlakuan kepada pokok tomato (Lycopersicon esculentum Mill) varieti MT1 telah dikaji. Pertumbuhan dan hasil tomato diukur dan nilai signifikan daripada pelbagai faktor telah ditentukan. Pertumbuhan tomato ditentukan melalui tinggi, berat kering, panjang akar dan saiz daun. Berat dan jumlah buah bagi setiap pokok telah diambil kira dan diameter buah tomato juga telah diukur. Pelbagai tindak balas pokok tomato dapat diperhatikan seperti yang dilaporkan oleh Passam et al. (2007) dengan tindak balas pokok tomato pada aras nutrien yang tertentu mungkin berbeza mengikut kepelbagaian tanaman dan faktor luaran seperti amalan pertanian, substrat dan keadaan persekitaran.

\section{TINGGI POKOK}

Analisis varians menunjukkan faktor kompos menyumbang secara signifikan terhadap tinggi pokok (Jadual 3). Manakala, faktor baja tidak menyumbang kepada ketinggian pokok. Faktor pestisid pula menunjukkan keputusan yang sama dengan faktor baja kecuali pada bulan Disember. Dalam kajian ini, pestisid yang digunakan mengandungi bahan aktif iaitu imidakloprid yang berkesan melindungi pokok daripada serangan serangga dan penyakit yang telah memberikan kesan terhadap ketinggian pokok setelah digunakan secara konsisten selama 8 bulan. Menurut Brandt dan Molgaard (2001), tiada kesan sistemik mengenai pestisid dan patogen dalam komposisi tumbuhan. Walau bagaimanapun, kesan yang ditunjukkan mungkin disebabkan akibat penyeimbangan sistem penanaman berbeza yang dialami oleh pokok yang memberi kesan yang pelbagai. Faktor kompos menyumbang kepada tinggi pokok mungkin disebabkan oleh aktiviti mikroorganisma yang menyumbang kepada penghasilan nutrien dan memudahkan penyerapan oleh akar tumbuhan. Kajian ini menunjukkan interaksi antara faktor pestisid $\times$ baja, pestisid $\times$ kompos, baja $\times$ kompos, pestisid $\times$ baja $\times$ kompos didapati tidak menyumbang kepada tinggi pokok kecuali baja x kompos pada bulan Jun (Jadual 3). Keputusan ini mungkin berpunca daripada interaksi antara beberapa faktor dengan fisiologi tumbuhan dan persekitaran (Sultan 2000).

JADUAL 3. Min kuasa dua bagi analisis varians kesan perlakuan terhadap tinggi pokok

\begin{tabular}{|c|c|c|c|c|c|c|c|}
\hline Faktor & DF & Jun & Julai & Ogos & Sept & Okt & Dis \\
\hline Pestisid & 1 & 1.02 & 200.08 & 1485.19 & 3267.00 & 7203.00 & $32188.52 *$ \\
\hline Baja & 3 & 78.85 & 1610.75 & 1963.35 & 829.81 & 1526.72 & $5152.63^{\prime}$ \\
\hline Kompos & 1 & $2310.19 *$ & $7203.00 *$ & $11193.52 *$ & $10800.00 *$ & $15265.33^{*}$ & 18057.52 \\
\hline Pestisid $\times$ Baja & 3 & 80.41 & 68.31 & 493.63 & 680.72 & 346.50 & 1710.24 \\
\hline Pestisid $\times$ Kompos & 1 & 256.69 & 456.33 & 858.52 & 752.08 & 3136.33 & 22837.69 \\
\hline Baja $\times$ Kompos & 3 & $279.58 *$ & 2022.89 & 2494.08 & 1416.61 & 1698.39 & 5115.47 \\
\hline Pestisid $\times$ Baja $\times$ Kompos & 3 & 187.85 & 269.56 & 231.85 & 370.47 & 335.16 & 9184.52 \\
\hline
\end{tabular}

$\mathrm{DF}=$ darjah kebebasan, *signifikan pada $\mathrm{p}<0.05$ 
Analisis varians antara faktor dan interaksinya tidak menunjukkan nilai tinggi pokok untuk setiap perlakuan (Jadual 3). Oleh sebab itu, purata ketinggian pokok untuk setiap rawatan dianalisis menggunakan perbezaan signifikan terkecil (LSD) ujian pelbagai perbandingan pos hoc. Keputusan menunjukkan ketinggian yang signifikan bagi pokok tomato berubah-ubah dalam bulan yang berbeza bagi setiap perlakuan. Contohnya perlakuan T11 signifikan pada bulan Jun, bagi bulan Julai adalah T8, T13 dan T3, bagi bulan Ogos adalah T3 dan T15, bagi bulan September adalah T1, T6, T3, T15, T13, T5, T9, T11 dan T8, bagi bulan Oktober (T3, T5, T1, T4, T9, T13, T11, T15, T7, T6, T8, T2, T14 dan T12) dan bulan Disember adalah perlakuan $\mathrm{T} 7$. Keberadaan nutrien yang berbeza untuk setiap perlakuan mungkin menentukan ketinggian pokok yang berubah-ubah bagi setiap bulan.

Perlakuan T10 (pestisid organik, kompos EFB, tanpa baja) menghasilkan pokok yang paling rendah dari Julai sehingga Disember secara signifikan selama 6 bulan berturut-turut (Jadual 4). Pokok dengan perlakuan T10 hanya bergantung pada nutrien yang diperoleh daripada EFB dan tanah tanpa tambahan daripada baja. Keadaan ini mungkin menyebabkan kurang sumber nutrien dan pokok hanya boleh mandiri dengan adanya cahaya matahari dan persekitaran nutrien yang rendah (Ennis et al. 2005). Oleh sebab itu, T10 menunjukkan ketinggian pokok yang kurang dan berat pokok yang tinggi secara signifikan $(\mathrm{p}<0.05)$ seperti dalam Jadual 4 dan Jadual 6. T10 juga menunjukkan adaptasi plastisiti semula jadi seperti diterangkan oleh Sultan (2000) menunjukkan sesetengah tumbuhan termasuk tomato boleh mengubah fenotip apabila perlu bermandiri dalam persekitaran terhad. Keputusan ini turut disokong oleh Moradi et al. (2014) yang menunjukkan penggunaan kompos EFB tanpa penambahan baja boleh meningkatkan berat kering tumbuhan dan tidak meningkatkan tinggi tumbuhan. Berdasarkan keputusan kajian tersebut, EFB membebaskan nutrien semasa pengomposan selama lapan bulan iaitu sama seperti tempoh di dalam kajian ini iaitu 8 bulan (Moradi et al. 2014).

JADUAL 4. Min tinggi tumbuhan dalam meter (m) bagi perlakuan berbeza

\begin{tabular}{ccccccc}
\hline Perlakuan & Jun & Julai & Ogos & Sep & Okt & Dis \\
\hline T1 & $1.02^{\mathrm{abc}}$ & $1.90^{\mathrm{ab}}$ & $2.17^{\mathrm{ab}}$ & $2.50^{\mathrm{a}}$ & $2.83^{\mathrm{a}}$ & $4.43^{\mathrm{abc}}$ \\
T2 & $0.78^{\mathrm{ef}}$ & $1.37^{\mathrm{de}}$ & $1.66^{\mathrm{bc}}$ & $2.06^{\mathrm{ab}}$ & $2.44^{\mathrm{a}}$ & $3.60^{\mathrm{bcd}}$ \\
T3 & $1.03^{\mathrm{abc}}$ & $1.94^{\mathrm{a}}$ & $2.32^{\mathrm{a}}$ & $2.39^{\mathrm{a}}$ & $2.89^{\mathrm{a}}$ & $3.80^{\mathrm{abcd}}$ \\
T4 & $0.88^{\mathrm{cdef}}$ & $1.53^{\mathrm{bcde}}$ & $1.83^{\mathrm{abc}}$ & $2.06^{\mathrm{ab}}$ & $2.77^{\mathrm{a}}$ & $4.76^{\mathrm{ab}}$ \\
T5 & $0.96^{\mathrm{abcd}}$ & $1.81^{\mathrm{abc}}$ & $2.17^{\mathrm{ab}}$ & $2.29^{\mathrm{a}}$ & $2.86^{\mathrm{a}}$ & $4.14^{\mathrm{abcd}}$ \\
T6 & $0.86^{\text {def }}$ & $1.81^{\mathrm{abc}}$ & $2.23^{\mathrm{ab}}$ & $2.34^{\mathrm{a}}$ & $2.66^{\mathrm{a}}$ & $4.60^{\mathrm{ab}}$ \\
T7 & $0.90^{\mathrm{cde}}$ & $1.75^{\mathrm{abcd}}$ & $2.1^{\mathrm{ab}}$ & $2.40^{\mathrm{a}}$ & $2.69^{\mathrm{a}}$ & $4.90^{\mathrm{a}}$ \\
T8 & $1.01^{\mathrm{abc}}$ & $1.96^{\mathrm{a}}$ & $2.16^{\mathrm{ab}}$ & $2.24^{\mathrm{a}}$ & $2.62^{\mathrm{a}}$ & $4.49^{\mathrm{abc}}$ \\
T9 & $0.96^{\mathrm{abcd}}$ & $1.81^{\mathrm{abc}}$ & $2.16^{\mathrm{ab}}$ & $2.29^{\mathrm{a}}$ & $2.76^{\mathrm{a}}$ & $4.04^{\mathrm{abcd}}$ \\
T10 & $0.83^{\mathrm{def}}$ & $1.30^{\mathrm{e}}$ & $1.38^{\mathrm{c}}$ & $1.51^{\mathrm{b}}$ & $1.74^{\mathrm{b}}$ & $3.08^{\mathrm{d}}$ \\
T11 & $1.07^{\mathrm{a}}$ & $1.83^{\mathrm{abc}}$ & $2.22^{\mathrm{ab}}$ & $2.28^{\mathrm{a}}$ & $2.74^{\mathrm{a}}$ & $4.77^{\mathrm{ab}}$ \\
T12 & $0.74^{\mathrm{f}}$ & $1.47^{\mathrm{cde}}$ & $1.83^{\mathrm{abc}}$ & $2.08^{\mathrm{ab}}$ & $2.39^{\mathrm{a}}$ & $3.26^{\mathrm{cd}}$ \\
T13 & $1.06^{\mathrm{ab}}$ & $1.95^{\mathrm{a}}$ & $2.03^{\mathrm{ab}}$ & $2.32^{\mathrm{a}}$ & $2.74^{\mathrm{a}}$ & $3.99^{\mathrm{abcd}}$ \\
T14 & $0.91^{\mathrm{bcde}}$ & $1.68^{\mathrm{abcde}}$ & $1.82^{\mathrm{abc}}$ & $2.04^{\mathrm{ab}}$ & $2.39^{\mathrm{a}}$ & $3.72^{\mathrm{abcd}}$ \\
T15 & $1.02^{\mathrm{abc}}$ & $1.89^{\mathrm{ab}}$ & $2.24^{\mathrm{a}}$ & $2.36^{\mathrm{a}}$ & $2.70^{\mathrm{a}}$ & $4.13^{\mathrm{abcd}}$ \\
T16 & $0.88^{\mathrm{cdef}}$ & $1.80^{\mathrm{abc}}$ & $2.07^{\mathrm{ab}}$ & $2.10^{\mathrm{ab}}$ & $2.34^{\mathrm{ab}}$ & $3.58^{\mathrm{bcd}}$ \\
\hline
\end{tabular}

Huruf berbeza dalam lajur yang sama menunjukkan perbezaan signifikan $(\mathrm{p}<0.05)$

\section{BERAT KERING POKOK, PANJANG AKAR DAN SAIZ DAUN}

Analisis varians berat kering (daun, batang dan akar), panjang akar dan saiz daun seperti dalam Jadual 5. Faktor pestisid menunjukkan kesan yang signifikan $(\mathrm{p}<0.05)$ terhadap berat kering daun faktor baja pula menyumbang secara signifikan $(\mathrm{p}<0.05)$ terhadap saiz daun. Interaksi 
faktor pestisid $\times$ baja tidak signifikan $(\mathrm{p}>0.05)$ terhadap berat kering pokok iaitu daun, akar dan batang. Hanya saiz daun yang signifikan dalam interaksi faktor pestisid $\times$ kompos. Didapati berat daun dan akar adalah signifikan terhadap interaksi baja $\times$ kompos. Interaksi semua faktor iaitu pestisid $\times$ baja $\times$ kompos hanya signifikan terhadap saiz daun. Oleh sebab itu, dalam keputusan interaksi antara baja $\times$ kompos menunjukkan kelebihan gabungan penggunaan kompos dan baja. Ini disebabkan oleh penggunaan kompos memperbaiki tanah dan menggalakkan pembentukan akar (Canellas et al. 2002). Pembentukan akar yang baik membolehkan tumbuhan menyerap air dan nutrien daripada medium penanaman yang menyumbang kepada berat daun. Keputusan ini adalah sama seperti Canellas et al. (2002) yang melaporkan pertumbuhan pokok jagung menggunakan kompos menyumbang kepada pertumbuhan akar lateral benih jagung (Zea mays). Baja kimia membebaskan nutrien secara cepat kepada pokok untuk digunakan (Ilupeju et al. 2015). Baja organik pula membebaskan nutrien dengan perlahan ke dalam medium penanaman. Oleh sebab itu, kedua-dua faktor kompos dan baja adalah penting dalam pertumbuhan pokok.

JADUAL 5. Nilai min kuasa dua bagi analisis varians terhadap berat kering pokok (daun, batang dan akar), panjang akar dan saiz daun

\begin{tabular}{lllllll}
\hline Faktor & DF & Berat daun & Berat batang & Berat akar & $\begin{array}{l}\text { Panjang } \\
\text { akar }\end{array}$ & Saiz daun \\
\hline Pestisid & 1 & $12838.02^{*}$ & 1121.33 & 546.75 & 1160.33 & 343.89 \\
Baja & 3 & 5081.68 & 17248.94 & 869.80 & 126.92 & $237.02^{*}$ \\
Kompos & 1 & 58.52 & 120.33 & $3040.08^{*}$ & 1026.75 & $292.54^{*}$ \\
Pestisid $\times$ Baja & 3 & 1243.63 & 4944.16 & 320.69 & 286.83 & 49.09 \\
Pestisid $\times$ Kompos & 1 & 595.02 & 2883.00 & 270.75 & 65.33 & $329.8^{*}$ \\
Baja $\times$ Kompos & 3 & $8550.13^{*}$ & 9414.27 & $2163.47^{*}$ & 360.14 & 62.88 \\
Pestisid $\times$ Baja $\times$ Kompos & 3 & 4666.74 & 9528.50 & 700.58 & 219.94 & $154.08^{*}$ \\
\hline
\end{tabular}

$\mathrm{DF}=$ darjah kebebasan, ${ }^{*}$ signifikan pada $\mathrm{p}<0.05$

Jadual 6 menunjukkan perlakuan T10 menghasilkan berat kering daun yang paling banyak iaitu $200.0 \mathrm{~g}$ sementara perlakuan T12 menghasilkan berat kering daun yang paling rendah sebanyak $26.7 \mathrm{~g}$. Penghasilan berat kering batang adalah seperti berikut T6 (261.3 g), T10 (245.7 g), T8 (229.3 g) dan T13 (228.0 g) adalah lebih tinggi secara signifikan $(\mathrm{p}<0.05)$ berbanding perlakuan lain. Berat akar T3 (91.0 g) pula adalah lebih berat $(\mathrm{p}<0.05)$ berbanding T2 (27.3 g), T10 (27.0) dan T12 (26.3) bagi berat kering akar. Perlakuan T12 (73.0 $\mathrm{cm})$ menunjukkan akar yang paling panjang sementara T1 $(33.3 \mathrm{~cm})$ menunjukkan panjang akar yang paling pendek secara signifikan $(p<0.05)$. Saiz daun yang paling besar ditunjukkan oleh perlakuan T11 $\left(48.0 \mathrm{~cm}^{2}\right)$ dan T3 $\left(46.06 \mathrm{~cm}^{2}\right)$ sementara saiz daun yang paling kecil adalah T2 $\left(19.78 \mathrm{~cm}^{2}\right)$.

Perbandingan antara perlakuan bagi berat kering pokok, panjang akar dan saiz daun dalam Jadual 6 menunjukkan perlakuan T10 (pestisid organik, kompos
EFB, tanpa baja) mempunyai berat pokok yang paling tinggi dan telah dibincang dalam perenggan sebelumnya. Perlakuan T12 (pestisid organik, kompos EFB, baja organik) menunjukkan nilai terendah bagi parameter berat kering (daun, akar, batang) tetapi nilai paling tinggi bagi panjang akar secara signifikan $(p<0.05)$. Saiz daun bagi perlakuan T12 adalah tinggi tetapi tidak berbeza secara signifikan dengan perlakuan lain. Keputusan ini adalah bertentangan dengan penemuan oleh AdeOluwa dan Adeoye (2008) yang mendapati pokok kelapa sawit yang berusia sepuluh bulan yang diberi perlakuan kompos EFB dan baja najis lembu mempunyai berat kering pokok yang tinggi. Pokok lain seperti bunga kobis hibrid seperti yang dilaporkan oleh Asiah et al. (2004) menunjukkan dua kali ganda berat kering pokok dan saiz daun apabila ditanam menggunakan kompos najis lembu berbanding kompos EFB. Kajian lain oleh Palanivell et al. (2013) menunjukkan penggunaan kompos EFB terhadap pokok jagung tidak meningkatkan diameter pokok, tinggi pokok 
dan berat kering pokok secara signifikan $(p<0.05)$. Dalam kajian ini dapat disimpulkan bahawa penambahan baja organik ke dalam medium penanaman mengandungi kompos EFB akan mengurangkan berat kering pokok dan meningkatkan panjang akar. Ini kerana kebanyakan sisa pertanian yang dihasilkan daripada aktiviti pertanian dan industri perhutanan mempunyai ciri yang baik untuk diaplikasikan pada tanah dan meningkatkan kesuburan dan kualiti tanah. Selain itu, pelbagai jenis kompos dan tanah akan mempengaruhi biojisim pokok (Wan Rasidah et al. 2013). Perlakuan lain menunjukkan perbezaan namun tidak signifikan ( $\mathrm{p}>0.05)$. Kajian oleh Wan Rasidah et al. (2013) menunjukkan penggunaan kompos EFB memberikan biojisim yang lebih baik pada tumbuhan Orthosiphon stamineus (Misai kucing) apabila menggunakan tanah gambut. Keputusan ini adalah disebabkan nisbah karbon nitrogen $(\mathrm{C} / \mathrm{N})$ yang menyumbang kepada keberadaan nutrien pada bahagian mikro akar.

Pokok yang diberi perlakuan T11 (pestisid organik) dan T3 (pestisid kimia) menunjukkan penghasilan saiz daun yang besar secara signifikan $(\mathrm{p}<0.05)$ berbanding dengan perlakuan lain (Jadual 6). Kedua-dua pokok ditanam dalam medium mengandungi kompos najis lembu dan ditambah baja organik. Data ini menunjukkan penggunaan najis lembu menghasilkan saiz daun yang besar membolehkan pokok menyerap matahari dan melakukan tindak balas fostosintesis. Keputusan ini adalah sama seperti yang dilaporkan oleh Liu et al. (2014) yang menunjukkan perlakuan dengan baja organik meningkatkan saiz daun salad lettuce. Kajian oleh Ilupeju et al. (2015) juga melaporkan penggunaan baja organik mempunyai potensi dalam meningkatkan pertumbuhan, hasil buah dan kandungan zat makanan dalam varieti tomato. Ini disebabkan terdapat jumlah nutrien yang optimum bagi pokok untuk menyerap dan menggunakannya akan membolehkan pokok menyerlahkan potensi optimumnya (Ilupeju et al. 2015). Keputusan daripada kajian ini menunjukkan jumlah saiz daun dan bilangan buah per pokok didapati rendah sekiranya berat kering akar adalah rendah.

JADUAL 6. Nilai min berat kering pokok (daun, batang dan akar), panjang akar dan jumlah saiz daun untuk perlakuan berbeza

\begin{tabular}{lccccc}
\hline Perlakuan & $\begin{array}{c}\text { Berat daun } \\
(\mathrm{g})\end{array}$ & $\begin{array}{c}\text { Berat batang } \\
(\mathrm{g})\end{array}$ & $\begin{array}{c}\text { Berat akar } \\
(\mathrm{g})\end{array}$ & $\begin{array}{c}\text { Panjang akar } \\
(\mathrm{cm})\end{array}$ & $\begin{array}{c}\text { Saiz daun } \\
\left(\mathrm{cm}^{2}\right)\end{array}$ \\
\hline T1 & $77.3^{\mathrm{bc}}$ & $153.3^{\mathrm{ab}}$ & $64.3^{\mathrm{abc}}$ & $33.3^{\mathrm{b}}$ & $34.06^{\mathrm{bcd}}$ \\
T2 & $95.3^{\mathrm{bc}}$ & $142.7^{\mathrm{ab}}$ & $27.3^{\mathrm{d}}$ & $47.3^{\mathrm{ab}}$ & $19.78^{\mathrm{e}}$ \\
T3 & $82.7^{\mathrm{bc}}$ & $144.7^{\mathrm{ab}}$ & $91.0^{\mathrm{a}}$ & $43.0^{\mathrm{ab}}$ & $46.06^{\mathrm{a}}$ \\
T4 & $60.3^{\mathrm{bc}}$ & $85.7^{\mathrm{b}}$ & $41.7^{\mathrm{bcd}}$ & $53.0^{\mathrm{ab}}$ & $32.56^{\mathrm{cd}}$ \\
T5 & $51.7^{\mathrm{bc}}$ & $184.0^{\mathrm{ab}}$ & $35.0^{\mathrm{cd}}$ & $42.3^{\mathrm{ab}}$ & $38.67^{\mathrm{abcd}}$ \\
T6 & $59.7^{\mathrm{bc}}$ & $261.3^{\mathrm{a}}$ & $36.0^{\mathrm{cd}}$ & $61.7^{\mathrm{ab}}$ & $32.56^{\mathrm{cd}}$ \\
T7 & $51.7^{\mathrm{bc}}$ & $162.3^{\mathrm{ab}}$ & $30.7^{\mathrm{cd}}$ & $53.7^{\mathrm{ab}}$ & $38.00^{\mathrm{abcd}}$ \\
T8 & $67.3^{\mathrm{bc}}$ & $229.3^{\mathrm{a}}$ & $71.3^{\mathrm{ab}}$ & $38.0^{\mathrm{ab}}$ & $31.17^{\mathrm{de}}$ \\
T9 & $89.0^{\mathrm{bc}}$ & $137.3^{\mathrm{ab}}$ & $43.3^{\mathrm{bcd}}$ & $63.7^{\mathrm{ab}}$ & $28.11^{\mathrm{de}}$ \\
T10 & $200.0^{\mathrm{a}}$ & $245.7^{\mathrm{a}}$ & $27.0^{\mathrm{d}}$ & $63.0^{\mathrm{ab}}$ & $45.00^{\mathrm{ab}}$ \\
T11 & $133.3^{\mathrm{ab}}$ & $159.7^{\mathrm{ab}}$ & $70.7^{\mathrm{ab}}$ & $46.0^{\mathrm{ab}}$ & $48.00^{\mathrm{a}}$ \\
T12 & $26.7^{\mathrm{c}}$ & $68.7^{\mathrm{b}}$ & $26.3^{\mathrm{d}}$ & $73.0^{\mathrm{a}}$ & $43.11^{\mathrm{abc}}$ \\
T13 & $88.0^{\mathrm{bc}}$ & $228.0^{\mathrm{a}}$ & $48.3^{\mathrm{bcd}}$ & $47.7^{\mathrm{ab}}$ & $37.00^{\mathrm{abcd}}$ \\
T14 & $91.7^{\mathrm{bc}}$ & $152.3^{\mathrm{ab}}$ & $36.0^{\mathrm{cd}}$ & $62.3^{\mathrm{ab}}$ & $34.00^{\mathrm{bcd}}$ \\
T15 & $112.0^{\mathrm{b}}$ & $142.7^{\mathrm{ab}}$ & $50.7^{\mathrm{bcd}}$ & $45.0^{\mathrm{ab}}$ & $44.11^{\mathrm{abc}}$ \\
\hline & $67.0^{\mathrm{bc}}$ & $151.7^{\mathrm{ab}}$ & $41.0^{\mathrm{bcd}}$ & $50.3^{\mathrm{ab}}$ & $36.33^{\mathrm{abcd}}$ \\
\hline
\end{tabular}

Huruf berbeza dalam lajur yang sama menunjukkan perbezaan signifikan $(\mathrm{p}<0.05)$ 


\section{BERAT, BILANGAN DAN DIAMETER TOMATO}

Tomato dinilai berdasarkan berat, bilangan dan diameter seperti Ilupeju et al. (2015). Disebabkan hasil buah adalah tujuan utama dalam penanaman tomato, maka jumlah berat buah, bilangan buah per pokok dan diameter dinilai. Analisis varians kesan perlakuan terhadap berat buah, bilangan buah dan diameter buah ditunjukkan dalam Jadual 7. Bagi faktor baja, jumlah berat buah menunjukkan perbezaan signifikan pada aras $\mathrm{p}<0.05$ manakala faktor kompos menunjukkan perbezaan signifikan pada bilangan buah per pokok pada aras keyakinan yang sama. Faktor dan interaksi faktor yang lain tidak menunjukkan perbezaan signifikan terhadap berat, bilangan dan diameter buah. Semua interaksi antara faktor juga didapati tidak menyumbang kepada hasil tomato.

JADUAL 7. Nilai min kuasa dua analisis varians sumber variasi terhadap berat buah, bilangan dan diameter

\begin{tabular}{lcccc}
\hline Faktor & DF & Jumlah berat buah & Bilangan buah per pokok & Diameter buah \\
\hline Pestisid & 1 & 388674.01 & 1344.08 & 4.74 \\
Baja & 3 & $137896.66^{*}$ & 130.94 & 33.95 \\
Kompos & 1 & 54085.29 & $520.08^{*}$ & 17.16 \\
Pestisid $\times$ Baja & 3 & 8618.39 & 58.92 & 38.49 \\
Pestisid $\times$ Kompos & 1 & 116.00 & 65.33 & 0.04 \\
Baja $\times$ Kompos & 3 & 39233.44 & 47.25 & 11.39 \\
Pestisid $\times$ Baja $\times$ Kompos & 3 & 15679.45 & 21.39 & 99.98 \\
\hline
\end{tabular}

$\mathrm{DF}=$ darjah kebebasan, $*$ signifikan pada nilai $\mathrm{p}<0.05$

Dalam kajian ini, berat buah paling tinggi dan bilangan buah per pokok paling banyak ditunjukkan oleh pokok dengan perlakuan T15 (560.3 g, 32 buah) seperti ditunjukkan dalam Jadual 8. Pokok tomato yang diberi perlakuan T15 menunjukkan perbezaan min signifikan terhadap jumlah berat dan bilangan buah pada aras $\mathrm{p}<0.05$. T6 (54.6 g) merupakan nilai terendah jumlah berat buah secara signifikan $(\mathrm{p}<0.05)$. Perlakuan yang mencatatkan bilangan buah per pokok yang paling sedikit adalah T2 iaitu sebanyak 2 biji sahaja. Perlakuan T12 (39.61 mm) telah menunjukkan diameter buah paling besar secara signifikan $(\mathrm{p}<0.05)$ dan yang paling kecil ditunjukkan oleh T10 (26.64 mm).

Hasil bilangan buah tomato adalah signifikan tinggi $(\mathrm{p}<0.05)$ ditunjukkan oleh T15 (pestisid organik, kompos najis lembu, campuran baja kimia dan organik) tetapi tidak signifikan dalam diameter buah. Keputusan ini selari dengan Abbasi et al. (2002) yang menunjukkan penggunaan kompos menghasilkan buah yang lebih besar, manakala Carrera et al. (2007) melaporkan peningkatan hasil tomato mungkin disebabkan kompos telah menambahbaik struktur komuniti mikrob selanjutnya meningkatkan kitar nutrien dalam tanah. Keberadaan nutrien meningkatkan hasil tomato. Buah bagi pokok tomato dengan perlakuan T12 (pestisid organik, kompos EFB dan baja organik) tidak menunjukkan nilai yang signifikan dalam hasil iaitu berat buah dan bilangan buah tomato berbanding perlakuan yang lain (Jadual 8). Keputusan ini adalah sama dengan keputusan diameter buah dalam kajian oleh Wira et al. (2011), yang menunjukkan buah rock melon yang diberi perlakuan kompos EFB akan mempunyai saiz dan diameter yang besar.

Diameter tomato yang terkecil ditunjukkan oleh pokok dengan perlakuan T10 (pestisid organik, kompos EFB, baja kimia) secara signifikan $(\mathrm{p}<0.05)$. Perlakuan lain menghasilkan buah yang berbeza-beza diameter namun tidak signifikan $(\mathrm{p}>0.05)$. Berat buah yang paling rendah ditunjukkan oleh pokok dengan perlakuan T6 (pestisid kimia, kompos EFB, tanpa baja) seperti dalam Jadual 8. Keseluruhnnya, hasil buah tomato menunjukkan bahawa pokok perlu diperkaya dengan baja bagi memastikan nutrien yang mencukupi untuk pertumbuhan dan penghasilan buah. Keputusan dalam kajian ini turut disokong oleh kajian Law-Ogbomo dan Egharevba (2009) yang menunjukkan pokok dengan perlakuan baja menghasilkan pertumbuhan yang baik dan hasil yang tinggi kerana baja meningkatkan kesuburan tanah apabila digunakan dalam kuantiti yang bertepatan. Daripada keputusan, ia menunjukkan penggunaan kompos EFB adalah bersesuaian dengan baja organik dan pestisid organik. 
JADUAL 8. Min bagi buah (jumlah berat, bilangan buah per pokok dan diameter) bagi perlakuan berbeza

\begin{tabular}{llll}
\hline Perlakuan & \multicolumn{1}{c}{$\begin{array}{l}\text { Jumlah berat buah } \\
\text { (g) }\end{array}$} & \multicolumn{1}{c}{ Bilangan buah per } & Diameter buah $(\mathrm{mm})$ \\
\hline T1 & $141.5^{\mathrm{de}}$ & $9.67^{\mathrm{cd}}$ & $28.8^{\mathrm{bc}}$ \\
T2 & $70.3^{\mathrm{de}}$ & $2.33^{\mathrm{d}}$ & $38.1^{\mathrm{ab}}$ \\
T3 & $199.7^{\mathrm{cde}}$ & $8.33^{\mathrm{cd}}$ & $35.1^{\mathrm{abc}}$ \\
T4 & $306.6^{\mathrm{abcde}}$ & $11.00^{\mathrm{cd}}$ & $34.8^{\mathrm{abc}}$ \\
T5 & $190.9^{\mathrm{cde}}$ & $11.33^{\mathrm{cd}}$ & $30.3^{\mathrm{abc}}$ \\
T6 & $54.6^{\mathrm{e}}$ & $6.00^{\mathrm{cd}}$ & $28.29^{\mathrm{bc}}$ \\
T7 & $383.1^{\mathrm{abcd}}$ & $15.67^{\mathrm{bc}}$ & $35.16^{\mathrm{abc}}$ \\
T8 & $227.6^{\mathrm{bcde}}$ & $8.67^{\mathrm{cd}}$ & $32.77^{\mathrm{abc}}$ \\
T9 & $359.1^{\mathrm{abcde}}$ & $25.67^{\mathrm{ab}}$ & $34.02^{\mathrm{abc}}$ \\
T10 & $188.9^{\mathrm{cde}}$ & $14.67^{\mathrm{bcd}}$ & $26.64^{\mathrm{c}}$ \\
T11 & $491.3^{\mathrm{abc}}$ & $24.67^{\mathrm{ab}}$ & $32.28^{\mathrm{abc}}$ \\
T12 & $532.5^{\mathrm{ab}}$ & $17.33^{\mathrm{bc}}$ & $39.61^{\mathrm{a}}$ \\
T13 & $236.8^{\mathrm{bcde}}$ & $14.33^{\mathrm{bcd}}$ & $34.90^{\mathrm{abc}}$ \\
T14 & $310.0^{\mathrm{abcde}}$ & $11.33^{\mathrm{cd}}$ & $34.47^{\mathrm{abc}}$ \\
T15 & $560.3^{\mathrm{a}}$ & $32.00^{\mathrm{a}}$ & $30.47^{\mathrm{abc}}$ \\
T16 & $335.1^{\mathrm{abcde}}$ & $17.67^{\mathrm{bc}}$ & $35.97^{\mathrm{abc}}$ \\
\hline
\end{tabular}

Huruf berbeza dalam lajur yang sama menunjukkan perbezaan signifikan $(\mathrm{p}<0.05)$

\section{KESIMPULAN}

Kajian dijalankan bagi menilai hasil tomato melalui perlakuan yang berbeza iaitu T1 sehingga T16. Sebagai kesimpulannya, perlakuan T15 (pestisid organik, kompos najis lembu, campuran baja kimia dan organik) menghasilkan jumlah berat dan bilangan buah tomato yang signifikan $(\mathrm{p}<0.05)$, manakala penggunaan pestisid kimia, kompos EFB dan baja kimia (T12) menunjukkan hasil tomato paling sedikit secara signifikan $(\mathrm{p}<0.05)$. Oleh sebab itu, bagi menggalakkan penggunaan kompos EFB, penambahan baja organik dan penggunaan pestisid organik disarankan bagi meningkatkan hasil tomato.

\section{PENGHARGAAN}

Pengarang merakamkan ucapan terima kasih kepada Universiti Kebangsaan Malaysia untuk sokongan yang berterusan dalam menyediakan kemudahan penyelidikan. Kajian ini dibiayai dan disokong oleh geran ST-2014-016.

\section{RUJUKAN}

Abbasi, P.A., Al-Dahmani, J., Sahin, F., Hoitink, H.A.J. \& Miller, S.A. 2002. Effect of compost amendments on disease severity and yield of tomato in conventional and organic production systems. Plant Disease 86(2): 156-161.

AdeOluwa, O.O. \& Adeoye, G.O. 2008. Potential of Oil Palm Empty Fruit Bunch (EFB) as Fertilizer in Oil Palm (Elaeis guineensis L Jacq.) Nurseries. $16^{\text {th }}$ IFOAM Organic World Congress, Modena, Italy, $16^{\text {th }}-20^{\text {th }}$ June 2008.

Asiah, A., Mohd Razi, I., Mohd Khanif, Y., Marziah, M. \& Shaharuddin, M. 2004. Physical and chemical properties of coconut coir dust and oil palm empty fruit bunch and the growth of hybrid heat tolerant cauliflower plant. Pertanika Journal of Tropical Agricultural Science 27(2): 121-133.

Asis, T., Zahrim, A.Y. \& Assis, K. 2017. Analisis prestasi nutrien pengkomposan sisa industri sawit skala industri dalam tempoh tiga tahun. Sains Malaysiana 46(8): 1201-1210.

Brandt, K. \& Mølgaard, J.P. 2001. Organic agriculture: Does it enhance or reduce the nutritional value of plant foods? Journal of the Science of Food and Agriculture 81: 924-931 doi:10.1002/jsfa.903. 
Canellas, L.P., Olivares, F.L., Okorokova-Fac, anha, A.L. \& Fac, anha, A.R. 2002. Humic acids isolated from earthworm compost enhance root elongation, lateral root emergence, and plasma membrane $\mathrm{H}^{+}$-ATPase activity in maize roots. Plant Physiology 130(4): 1951-1957.

Carrera, L.M., Buyer, J.S., Vinyard, B., Abdul-Baki, A.A., Sikora, L.J. \& Teasdale, J.R. 2007. Effects of cover crops, compost, and manure amendments on soil microbial community structure in tomato production systems. Applied Soil Ecology 37(3): 247-255

Chong, P.S., Jamaliah, M.J., Shuhaida, H., Lim, S.S., Sahilah, A.M. \& Mohd Tusirin, M.N. 2013. Enhancement of batch biohydrogen production from prehydrolysate of acid treated oil palm empty fruit bunch. International Journal of Hydrogen Energy 38(22): 9592-9599.

Douglass, F.J., Thomas, D.L. \& Tara, L. 2009. Chapter 5: Growing media. In Nursery Manual for Native Plants: A Guide for Tribal Nurseries, Volume 1: Nursery Management. Agriculture Handbook 730, edited by Dumroese, R., Kasten, L., Landis, T. \& Thomas, D. Washington: U.S. Department of Agriculture, Forest Service. pp. 77-93.

Ennis, I.L., Bussell, W.T., Lewthwaite, J.R., Triggs, C.M., Egginton, Z. \& McKennie, S. 2005. Growth and yield measurements to detect treatment differences in tomato modern greenhouses. Agronomy New Zealand 35: 38-43.

Farahzety, A.M., Fatkhiah, M. \& Siti Aishah, H. 2009. Effects of empty fruit bunch (EFB) compost and indigenous microbes on growth performance of cabbage (Brassica oleracea var. Capitata). Transactions of the Malaysian Societyof Plant Physiology 18: 6-9.

Getachew, M. 2014. Effect of different potting mixture on the seedling growth and survival of Albizia Gummifera and Cordia Africana. Journal of Natural Sciences Research 4(3): 2224-3186.

Ilupeju, E.A., Akanbi, W.B., Olaniyi, J.O., Lawal, B.A., Ojo, M.A. \& Akintokun, P.O. 2015. Impact of organic and inorganic fertilizers on growth, fruit yield, nutritional and lycopene contents of three varieties of tomato (Lycopersicon esculentum (L.) Mill.) in Ogbomoso, Nigeria. African Journal of Biotechnology 14(31): 2424-2433.

Ismail, M.R., Sze, L.Y., Poulus, P. \& Ibrahim, H. 2004. The use of empty oil palm fruit bunch (EFB) compost as additive in coconut dust soilless system for vegetable crop production. ISHS Acta Horticulturae 644: International Symposium on Growing Media and Hydroponics 644(25): 193-198. http:// www.ishs.org/ishs-article/644_25.

Law-Ogbomo, K.E. \& Egharevba, R.K.A. 2009. Effects of planting density and NPK fertilizer application on yield and yield components of tomato (Lycospersicon esculentum Mill) in forest location. World Journal of Agricultural Sciences 5(2): 152-158.

Liu, C.W., Sung, Y., Chen, B.C. \& Lai, H.Y. 2014. Effects of nitrogen fertilizers on the growth and nitrate content of lettuce (Lactuca sativa L.). International Journal of Environmental Research and Public Health 11(4):4427-4440 doi: 10.3390/ijerph110404427.
Mahlia, T.M.I., Abdulmuin, M.Z., Alamsyah, T.M.I. \& Mukhlishien, D. 2001. An alternative energy source from palm wastes industry for Malaysia and Indonesia. Energy Conversion Management 42: 2109-2118.

Mohd Razi, I. \& Dalia, S. 1995. Growth, physiological processes and yield of tomatoes grown in different root zone volumes using sand culture. Pertanika Journal of Tropical Agricultural Science 18(2): 141-147.

Moradi, A., Teh, C.B.S., Goh, K.J., Husni, M.H.A. \& Ishak, C.F. 2014. Decomposition and nutrient release temporal pattern of oil palm residues. Annals of Applied Biology 164: 208-219.

Noor, M., Md. Zahagir, A., Nasser, A.K. \& Ahsan, A. 2012. Effective composting of oil palm industrial waste by filamentous fungi: A review. Resources, Conservation and Recycling 58: 69-78.

Palanivell, P., Susilawati, K., Ahmed, O.H. \& Majid, N.M. 2013. Compost and crude humic substances produced from selected wastes and their effects on Zea mays L. nutrient uptake and growth. The Scientific World Journal 2013: 1-15.

Passam, H.C., Karapanos, I.C., Bebeli, P.J. \& Savvas, D. 2007. A review of recent research on tomato nutrition, breeding and post-harvest technology with reference to fruit quality. The European Journal of Plant Science and Biotechnology 1(1): 1-21.

Roslina, A. \& Rozhan, A.D. 2014. Competitiveness of Malaysian fresh agricultural and agro-based products in global markets: A case study in United Arab Emirates. Economic of Technology Management Review 9b: 93-101.

Singh, R.P., Embrandiri, A., Ibrahim, M.H. \& Esa, N. 2011. Management of biomass residues generated from palm oil mill: Vermicomposting a sustainable option. Resources, Conservation and Recycling 55(4): 423-434.

Sultan, S.E. 2000. Phenotypic plasticity for plant development, function and life history. Trends in Plant Science 5(120): 537-542.

Wan Rasidah, K., Rosazlin, A. \& Rozita, A. 2013. Application of organic residues for yield improvement of Orthosiphon stamineus on contrasting soils. Acta Biologica Indica 2(1): 277-283.

Wira, A.B., Mohd. Razi, I. \& Abd Jamil, Z. 2011. Composts as additives in coconut coir dust culture for growing rockmelon (Cucumis melo L.). Journal of Tropical Agriculture and Food Science 39(2): 229-237.

Department of Food Sciences

Faculty of Science and Technology

Universiti Kebangsaan Malaysia

43600 UKM Bangi, Selangor Darul Ehsan

Malaysia

*Corresponding author; email: sahilah@ukm.edu.my

Received: 31 October 2019

Accepted: 8 June 2020 